University of Nebraska - Lincoln

DigitalCommons@University of Nebraska - Lincoln

Management Department Faculty Publications

Management Department

2001

\title{
Leadership in Complex Organizations
}

\author{
Russ Marion \\ College of Education, Clemson University, Clemson, SC, marion2@clemson.edu \\ Mary Uhl-Bien \\ University of Nebraska-Lincoln, mbien2@unl.edu
}

Follow this and additional works at: https://digitalcommons.unl.edu/managementfacpub

Part of the Management Sciences and Quantitative Methods Commons

Marion, Russ and Uhl-Bien, Mary, "Leadership in Complex Organizations" (2001). Management Department Faculty Publications. 11.

https://digitalcommons.unl.edu/managementfacpub/11

This Article is brought to you for free and open access by the Management Department at DigitalCommons@University of Nebraska - Lincoln. It has been accepted for inclusion in Management Department Faculty Publications by an authorized administrator of DigitalCommons@University of Nebraska - Lincoln. 
Published in The Leadership Quarterly 12:4 (2001), pp. 389-418; doi 10.1016/S1048-

9843(01)00092-3 Copyright (C) 2002 Elsevier Science Inc. Used by permission. http:// www.elsevier.com/locate/leaqua

Winner of the Center for Creative Leadership/Leadership Quarterly

Best Paper Award for 2001.

Published online February 15, 2002.

\title{
Leadership in complex organizations
}

\author{
Russ Marion \\ College of Education, Clemson University, Clemson, SC 29634, USA \\ (Corresponding author: marion2@clemson.edu) \\ Mary Uhl-Bien \\ University of Central Florida, Orlando, FL, USA
}

\begin{abstract}
This paper asks how complexity theory informs the role of leadership in organizations. Complexity theory is a science of complexly interacting systems; it explores the nature of interaction and adaptation in such systems and how they influence such things as emergence, innovation, and fitness. We argue that complexity theory focuses leadership efforts on behaviors that enable organizational effectiveness, as opposed to determining or guiding effectiveness. Complexity science broadens conceptualizations of leadership from perspectives that are heavily invested in psychology and social psychology (e.g., human relations models) to include processes for managing dynamic systems and interconnectivity. We develop a definition of organizational complexity and apply it to leadership science, discuss strategies for enabling complexity and effectiveness, and delve into the relationship between complexity theory and other currently important leadership theories. The paper concludes with a discussion of possible implications for research strategies in the social sciences.
\end{abstract}

A "new science" of complexity theory has emerged in the physical sciences and recently made its way into the social sciences (Bak, 1996; Cartwright, 1991; Cronbach, 1988; Doll. 1989; Goldstein. 1995a, 1995b, 1996; Guastello, 1987, 1992; Marion, 1999; Marion \& Bacon, 1999; Nowak, May, \& Sigmund, 1995; Regine \& Lewin, 2000; Richardson \& Cilliers, 2001; Sterman, 1994; Wheatley, 1992). Though complexity science is nascent, researchers have suggested that it represents a "Kuhnian shift" for the physical sciences (Regine \& Lewin, 2000) and some have argued that the effect on the social sciences can be equally as dramatic (Marion, 1999). In the simplest terms, complexity theory moves away from linear, mechanistic views of the world, where simple cause-and-effect solutions are sought 
to explain physical and social phenomena, to a perspective of the world as nonlinear and organic, characterized by uncertainty and unpredictability (Regine \& Lewin, 2000). Classical science seeks order and stability, but complexity theorists see nature as too dynamic, unstable, unpredictable, and complexly stable to be described with such simple models (Prigogine, 1997).

This paradigm shift has potential for addressing problems faced in leadership research. Complexity science moves us away from reductionist perspectives that reduce holistic systems to isolated observations - a strategy which may simplify analysis and enable formulaic prescription but which ignores the significant influence of interactive dynamics. Instead, complexity theory encourages us to see organizations as complex adaptive systems composed of a diversity of agents who interact with one another, mutually affect one another, and in so doing generate novel behavior for the system as a whole (Marion, 1999; Regine \& Lewin, 2000). In this way, complexity science broadens conceptualizations of leadership from perspectives that are heavily invested in psychology and social psychology (e.g., human relations models) to include processes for managing dynamic systems and interconnectivity. It calls for us to rethink our approaches to leadership study, so much so that Hunt and Ropo (in press), building on Ilgen and Hulin (2000), consider complexity theory and its focus on dynamic systems as part of a "third discipline" for organizational research.

The purpose of this article is to provide an overview of complexity theory and how it applies to the study and the practice of leadership. We begin by briefly reviewing issues related to the study of leadership in general, and then discuss how complexity theory can help address some of the problems of the past. From there, we talk more specifically about complexity theory and its implications for leadership. We conclude by suggesting a structure for conducting research on the function of leadership in complex systems.

\section{Problems with leadership study}

In an essay exploring the transformation of leadership research over the latter half of the last century, Hunt (1999) described a period of leadership research he called the "doom and gloom" period (the 1970s to 1980s). This period was characterized by disillusionment with the developments of the field and the emergence of critics who claimed that leadership research told us very little and had out-lived its usefulness. As Hunt noted, this led many to wonder whether the study of leadership would survive. Specific criticisms included the belief that the number of unintegrated leadership models, prescriptions, and the like were mind boggling, much of the research was fragmentary, unrealistic, trivial, or dull, and the results were characterized by contradictions and Type III errors (solving the wrong problem precisely; Hunt, 1999). Other criticisms questioned the implicit assumption of the importance of leadership, arguing instead that there are situations in which leadership would have no effect (Kerr \& Jermier, 1978) or that theory proffered a romantic notion that leadership can explain the otherwise unexplainable (Meindl, Erlich, \& Dukerich, 1985). Hunt argued that this period ended with the advent of the "new leadership school" (Bryman, 1992), including visionary, transformational, and charismatic leadership approaches. He claimed 
this school constituted a paradigm shift in the leadership field.

We agree with Hunt (1999) that these new theoretical approaches transformed the field, and we acknowledge the continuing importance of current research that helps us incrementally increase our understanding of leadership issues. However, we also believe that, with some exceptions, existing approaches to the study of leadership remain heavily grounded in the premise that leadership is interpersonal influence ( Bass, 1985; Gardner \& Avolio, 1998; Graen \& Uhl-Bien, 1995; Katz \& Kahn, 1978), and therefore focus primarily on leader attributes and follower emotions (Hollander, 1978; House, Spangler, \& Woycke, 1991). While this is certainly a critical aspect of leadership, it may not tell the full story. Moreover, this emphasis may be related to problems of reductionism and determinism (e.g., the "gloom and doom" identified by Hunt, 1999) in the leadership field as a whole. Reductionism refers to research logic in which parts of a system are isolated and studied independently of the system from which they derive-the general idea is that, if one can understand the parts, one can draw conclusions about the whole. Determinism is the belief that all events are caused by preceding events and by knowing the preceding variables one can predict the future with certainty, what Prigogine (1997) calls "the Logic of Certainty."

Complexity theory approaches matters more holistically. Instead of viewing leadership just as interpersonal influence, complexity theory sees leadership as providing linkages to "emergent structures" (McKelvey, in press; Nicolis \& Prigogine, 1989) within and among organizations. As described by McKelvey (in press) at the macroleadership level (e.g., leadership of the organization; see Boal \& Hooijberg, 2001), applications of complexity theory suggest that the focus of leadership should be on how to foster and speed up the emergence of "distributed intelligence" (DI), which is a function of "strategically relevant human and social capital assets - the networked intellectual capabilities of human agents" (p. 1). McKelvey sees such macroleadership as revolving around the question: "What should CEOs do to foster emergent DI in their firms, speed its appreciation rate, and steer it in strategically important directions, all the while negating emergent bureaucracy?" (p. 1).

Along similar lines, we suggest that, at the microlevel (i.e., levels below the CEO or "upper echelon" of the organization; leadership in the organization, Boal \& Hooijberg, 2001), "complex leadership" involves creating the conditions that enable productive, but largely unspecified, future states. This suggestion recognizes that leaders cannot control the future (e.g., determinism) because in complex systems such as organizations, unpredictable (and sometimes unexplainable) internal dynamics will determine future conditions. Rather, microlevel complex leaders need to influence networks, creating atmospheres for formation of aggregates and meta-aggregates (e.g., the emergent structure concepts of complexity theory to be discussed below) in ways that permit innovation and dissemination of innovations so critical for "fitness" of the firm.

To explain these notions further, we present below an overview of the fundamental complexity theory concepts upon which we will build our arguments, and then proceed to a discussion of specific implications of complexity theory for micro-level leadership theory, research, and practice. We describe how complexity concepts can augment (not replace) our existing approaches and help move the field forward. 


\section{The logic of complexity theory}

As illustrated in Figure 1, complexity theory argues that emergent structures are produced by a combination of microdynamic (correlation, interaction, and randomness) and macrodynamic forces. Microdynamics represent the bottomup behaviors that occur when individuals interact, leading to both coordinated behavior and random behavior. The linkages created by these interactions may evolve into aggregates (i.e., combinations or linkages that represent a "system"), meta-aggregates (i.e., combinations of systems), and meta-meta-aggregates (combinations of meta-aggregates). Macrodynamics represent the emergence of the larger systems from the interactions at the microlevel. Macrobehaviors are driven by the microdynamics and by what we will call complex natural teleology (physics, autocatalysis, selection, and need), and are characterized by "bottom-up" coordination and by nonlinear behavior. These concepts and how they relate to

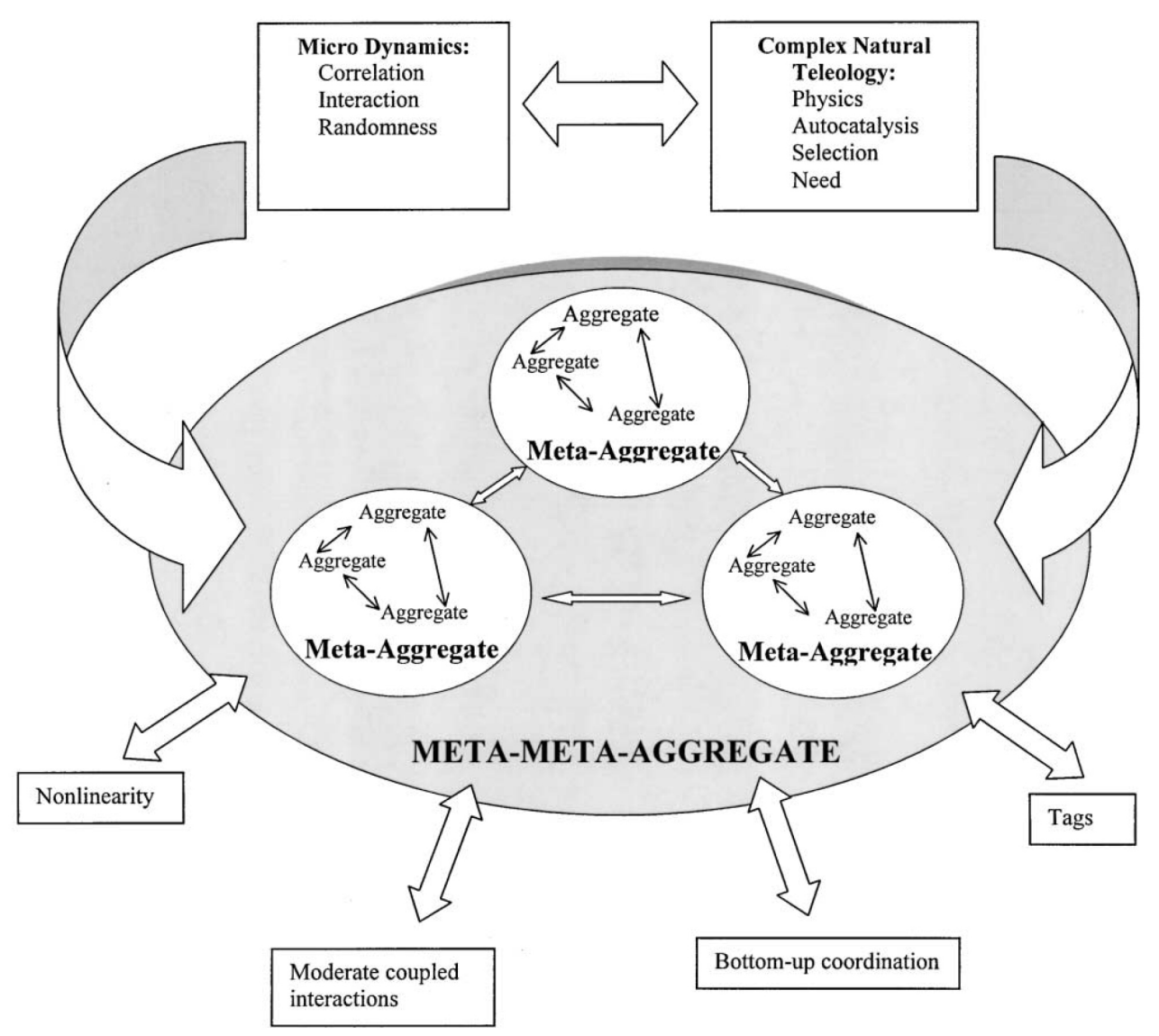

Figure 1. Microdynamics and complex natural teleology drive aggregation, or emergence. The process is influenced by coupling, bottom-up coordination, nonlinearity, and tags (which are also emergent dynamics). In emergence, aggregates evolve into meta-aggregates, which, in turn, evolve into meta-meta-aggregates. 
leadership are explained further below, beginning with microlevel complexity theory and moving to macrolevel dynamics.

\subsection{Microlevel complexity theory}

As discussed earlier, reductionism addresses the research logic which assumes that, if one can understand the parts of a system, one can understand the whole. In scientific research, approaches based on concepts of ultimate reductionism isolated and examined the trajectories of individual units (people, gas particles, etc.). This approach dominated the physical sciences in the 18th and 19th centuries. At the turn of the 20th century, however, physicists (notably Gibbs, Einstein, Maxwell, Boltzman, and others) revolutionized science by arguing that the trajectories of physical particles are prohibitively impossible to track. Further, even if one had the facilities for such a task, one would then have to track the trajectories of many particles, each with differing initial conditions, and combine the different trajectories into a coherent whole in order to understand the behavior of a system of particles (Gibbs, 1902). Gibbs and others proposed that scientists should instead consider the trajectories of ensembles, defined as a collection of identical systems with different initial conditions. If the possible future behaviors of such sets are statistically limited, one could conclude that the system's dynamics are ordered and predictable. Thus, began the study of population physics, a strategy for investigating physical behavior when the exact initial conditions of constituent units cannot be determined.

Social scientists likewise base their research strategies on the behaviors of ensembles. As in physics, it is prohibitive to define the varying initial conditions and trajectories of large numbers of people, then assemble the separate data into meaningful or interpretable information. Instead, we describe the statistical distribution of an ensemble at some point in time (its initial condition), and then reexamine that distribution after some exploratory intervention.

There are flaws in this logic however. Nobel Prize winner Ilya Prigogine (1997) argues that the logic of certainty that underlies this strategy is true only in simple, isolated systems - that is, they still ignore complex interactions among ensembles themselves. In more complex systems, interacting ensembles can, and often do, exhibit behaviors that cannot be related to a single ensemble's initial conditions (unexplained variation in regression analyses, for example). The error is attributable to small differences in initial conditions and to interaction among ensembles.

Consequently, we propose to expand the logic of ensembles: the behaviors of ensembles should be analyzed as products of the actions of independent variables, as has traditionally been the case, and of interaction among different ensembles (not to be confused with statistical interaction among variables).

Traditional research designs in leadership (and other social phenomena) tend to ignore interactions among ensembles. Such interaction, however, is a likely source of the often-considerable amount of unexplained variance left over in statistical analyses (Gell-Mann, 1994). Indeed, the magnitude of residuals was one of the rationales underlying the "doom and gloom" movement in leadership studies in the 1970s and 1980s (see Donaldson, 1996). Such residual is attributable to (a) the magnifying effect that interactions among ensembles exert on minor differ- 
ences in the initial conditions of the different ensembles and to (b) an irreducible random effect that is present in all interactive systems.

The interaction effect can be explained with an example. Consider two balls in a pinball machine released separately with careful positioning and spring tensing. The two balls will follow different trajectories because minute, logically inconsequential differences in initial conditions change the dynamics of interaction with various curved surfaces. Inexact positioning of initial conditions, however small, plus failure to consider interaction with other systems leads to significant errors of prediction. The same is true of social systems.

The irreducible random effect is likewise related to interaction, but in a different way. Interaction imparts both a measure of stable order within and among ensembles and a collateral measure of unpredictability. This phenomenon is a function of complex correlation (this usage differs from statistical correlation) - a feature of interacting systems in which particles impart a bit of their resonance (i.e., their own individualistic behaviors) to one another (see Poincaré, 1992 for discussion of random resonance in physical systems; see also Marion, 1999, and Prigogine, 1997). This causes the particles to resonate together to some degree. The coordinated resonance is not complete, however, for each particle retains a bit of its individualist resonance-hence, irreducible randomness.

All this has implications not only for leadership research; it has implications for leadership behavior itself (see Table 1). From the perspective of complexity theory, effective leadership is about learning to capitalize on interactive dynamics (correlation, randomness, and interaction) among and within organizational ensembles (defined as sets of individuals such as departments or other work groups that are characterized by common, direct interrelationships). Complexity theory confirms what we know intuitively (but typically ignore in practice): interaction and randomness means that leaders cannot always predict the future behaviors of organizational ensembles. Nor can they closely control those futures with deliberate interventions.

Thus, leadership effectiveness cannot be built exclusively around controlling the future; rather it depends on being able to foster interactive conditions that enable a productive future. Nor is it limited to human relations concepts that focus on the leader and his/her ability to foster relations with followers. Complex leaders cultivate largely undirected interactions among individuals, ensembles, and sets of ensembles to create uncontrolled futures. They understand organizational behavior in terms of global interactions rather than focusing narrowly on controlling local events. Complex leaders understand that the best innovations, structures, and solutions to problems are not necessarily those that they, with their limited wisdom, ordain, but those that emerge when interacting aggregates work through issues. Part of the role of leaders may involve exerting interpersonal influence (e.g., relationship-oriented behavior), but part of it may not (hence, the broader definition of leadership).

From a complexity perspective, relationship-oriented behaviors would enable effective networks rather than simply keeping peace or motivating enhanced effort. This changes the role of leadership away from "providing answers" or providing too much direction (e.g., initiating structure) to creating the conditions in which followers' behaviors can produce structure and innovation. There obviously are risks involved in this strategy, for failure can also come from surprise. 


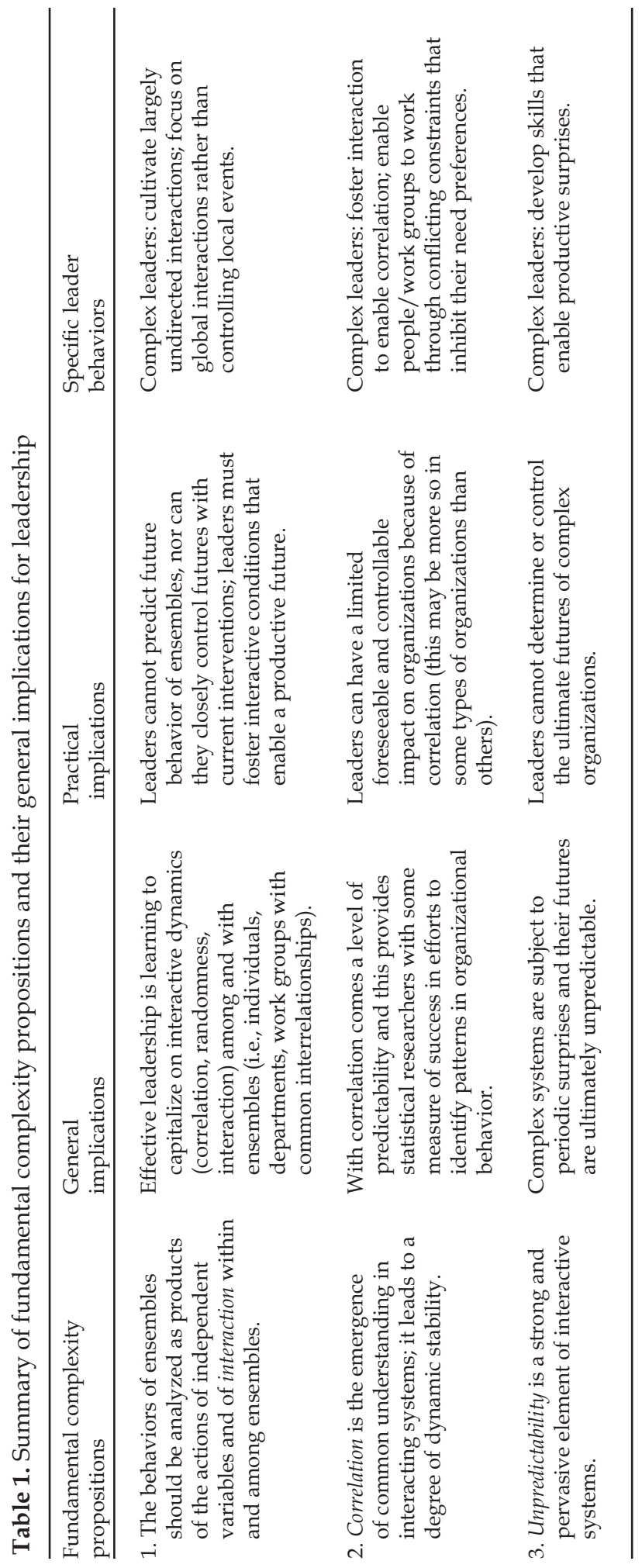


Complex systems exist on a cusp ("the edge of chaos," just shy of anarchy), risking catastrophe to enable creativity and fitness.

\subsection{Macrolevel complexity theory}

Interaction, correlation, and random effects among ensembles (what we term the microdynamics of complexity) lead to some interesting macrolevel dynamics, specifically dynamics related to the innovation, dissemination, and the emergence of order. At the microlevel, complexity theory is about interaction and correlation within ensembles. At the macrolevel, complexity theory is about structures and behaviors that emerge unbidden out of an interactive network of ensembles - behaviors that are self-generative, the products of interactive dynamics rather than external force (such as direct leadership intervention). Key characteristics of macrobehaviors include nonlinearity, bottom-up activity, and what Marion (1999) calls complex natural teleology (explained below). To align with the language of complexity theory, at this level, we will refer to ensembles as "aggregates" and to the complexity dynamics of interaction, correlation and random effects within and among aggregates as "emergence."

According to complexity theory, the emergence of structure and behavior in systems is possible for quite non-intuitive reasons: it occurs because of the very nature of the uncertainty, unpredictability, and nonlinearity - the microdynamics - that characterizes complex systems. Such behavior is inevitable in complex interacting systems - a fact that can be demonstrated mathematically. Yet, complex behavior is also stable in a very complex way. From a practical, human systems perspective, persistently interacting social networks create order, innovation, and fitness, but they ultimately elude control and prediction.

One's initial response to this might be discomfort, for leadership, as typically conceptualized, assumes that one can foresee the outcomes of given actions and control organizational activities. Of what use is leadership if the leader's behaviors do not shape a foreseeable desired future? Some complexity theorists (e.g., McKelvey, in press and Regine \& Lewin, 2000), like many leadership theorists (Cohen, March, \& Olsen, 1976; Donaldson, 1996; Manz \& Sims, 1987; Walton, 1985; Weick, 1976, 1979), have indeed concluded that command and control leadership may be a barrier rather than a gateway to organizational success. McKelvey (in press) extends this argument even further by suggesting that even charismatic leadership is command-and-control and inhibits proliferation of human and social capital, thus, seriously reducing the capacity of the organization to generate new product/niche strategies needed to sustain fitness.

We agree with them for the most part, but our position is somewhat more moderate. We argue that while complexity theory changes the way we should view leadership, it does not preemptively dismiss the importance of actively involved leadership, for such leadership can help enable complex behavior. Further, complexity theory does not dismiss prediction, particularly short-term prediction. This is because of dynamic stability that comes from complex correlation. Correlation was defined earlier as the sharing of resonances (i.e., individualistic behaviors) among interacting particles. We define it for social theory as the emergence of common understanding in interacting social systems. Correlation is the product of accommodations that evolve when different people or groups struggle 
to work out conflicting constraints that inhibit their need preferences. Marketing and manufacturing departments in production organizations, for example, have conflicting needs such as differing scheduling requirements. Interaction provides mechanisms by which such constraints can be addressed.

This bottom-up approach to resolving constraints is effective for dealing with complex networks of conflicting constraints, conditions that would stymie topdown efforts to resolve. Correlation among individuals and aggregates leads to a measure of dependable coordinated behavior - perhaps more so in some types of organizations than in others. Still, correlation characterizes all organizations; otherwise, they would not be "organized." With correlation comes a level of predictability on which leadership can operate.

Order and stability are not creative, however. If there were no surprises, if nature produced only safe and orderly growth, then there could be no variation on an original model (Prigogine, 1997). Even the ancient philosophers knew this. The Greek philosopher Epicurus said that "it would have been better to remain attached to the beliefs in gods rather than being slaves to the fates of physicists... [for] the latter... brings with it inviolable necessity" (Prigogine, 1997, p. 10). Complexity theorists argue that unpredictability is a second, crucial dimension of reality (correlation being the first), and that it is a strong and pervasive element of interactive systems (see Table 1).

Specifically, complex systems are just sufficiently dynamic to risk unpredictable change and to experience numerous small changes regularly, but sufficiently stable that they experience major change only infrequently. When they change, and particularly when they cross the divide to moderate or major change, newness emerges. The emergence of order, innovation, renewal, and even extinction are attributable to persistent interaction with its attendants, correlation and nonlinear surprise. Interaction is a constant and dominant characteristic of being social, one that creates both stability and change. This side of organization is more difficult for leaders to master; indeed, they would probably do best not to try to subjugate interactive dynamics. As we shall see, innovation and fitness are better served by bottom-up rather than top-down coordination.

These observations challenge traditional assumptions about causality in nature. At the very heart of traditional science is the assumption that all physical events can be understood if one only has sufficient command of pertinent initial conditions, that there is, ultimately, a basic rationality to nature. But nonlinearity in interacting systems compromises predictability in complex systems. As Levy (1992) states it:

A complex system is one whose component parts interact with sufficient intricacy that they cannot be predicted by standard linear equations; so many variables are at work in the system that its overall behavior can only be understood as an emergent consequence of the holistic sum of all the myriad behaviors embedded within. Reductionism does not work with complex systems, and it is now clear that a purely reductionist approach cannot be applied; ... in living systems the whole is more than the sum of its parts. This is the result of... complexity which allows certain behaviors and characteristics to emerge unbidden. (pp. 7-8)

In contradiction to Einstein, God does play dice with the universe. 


\subsection{Complex natural teleology}

Marion (1999) has consolidated and extrapolated the forces that drive the emergence of order from different sources in the complexity literature and has labeled them, collectively, "complex natural teleology." These forces are autocatalysis, need, physics, and natural selection. When applied to social systems, these concepts have direct implications for leadership.

Autocatalytic interaction (Kauffman, 1986, 1993, 1995) is the key to effective complex organizational behavior. It refers to a state of organization in which different units (people, departments, etc.) interact with one another within broad networks of interdependent behaviors. The intensity of such interactions (e.g., the number of other units on which a given unit is dependent) is limited, otherwise, autocatalytic interaction would be unwieldy. However, the nature of interaction is not predetermined or constrained by leadership fiat (rules, agendas, powerful leadership vision, etc.) or else autocatalysis would not be "auto." It would be incapable of capitalizing on surprise or the networked intelligence of its constituent units. That is, autocatalysis depends on emergent distributed intelligence (i.e., the networked intellectual capabilities of human agents; McKelvey, in press), which cannot be directed but can be enabled by leaders. Predictably, autocatalysis involves catalysts, which are events or things that speed up a process that could conceivably occur without the catalyst, but that would take forever to do so. A catalyst can also make things happen that would not happen otherwise. Autocatalyzation describes a process in which A leads to B, B leads to C, C leads to D, and D (perhaps in combination with B and/or C) catalyzes added production of $\mathrm{A}$, which started the whole process (or the process catalyzes production of some intermediary product: $\mathrm{D}+\mathrm{A}$ might catalyze production of $\mathrm{C}$, for example). This accounts for the process being called selfor autocatalyzing. A network of catalytic and noncatalytic events emerges and grows out of the dynamic, and the process feeds upon itself.

Holland (1995) observed the emergence of catalysts in his neural network simulations but he labeled them "tags." We define a social tag as any structure or information that catalyzes (enables or speeds up) certain social behaviors. A tag can include a new technology, an idea, a symbol (such as a flag), a symbolic act (the beating of Rodney King in 1992 was a symbol of police brutality and prejudice in Los Angeles), a group myth, or a belief. A tag can also be a leader, and this application of the concept is particularly important in this article. Leader tags emerge out of, and owe their existence to, interactive dynamics. That is, they rarely (and we suspect, never) create an interactive dynamic themselves; rather they are produced by the dynamic. Martin Luther King did not create the civil rights movement; rather he catalyzed its development. Churchill did not win the Battle over Great Britain, but he symbolized British courage. Nonetheless, tags are of significant importance in the development and nourishment of emergent dynamics and they demonstrate how leaders can be, and often are, involved in autocatalysis.

Autocatalysis requires no outside effort, no work by a central coordinating bureaucracy, no labor by the forces of natural selection; rather, it creates order for free. It appears unbidden, whether we want it or not. Birds flock naturally, without coordination (Reynolds, 1987); cities emerge despite the uncontrollable 
complexities of coordination posed by such massive networks (Holland, 1995). Order is the product of correlation and complex natural teleology - particularly autocatalysis. Reducing our argument to its essence, autocatalysis is what complex leaders work to enable (catalyze), and it is what complex behavior is all about.

Need, the second element of complex natural teleology, provides motivation for emergence. In the social sciences, it refers to the human drive to satisfy desires or needs. Deliberative need satisfaction is local, a function of the individual. People desire prestige, power, legitimacy, and resources, for example; or they seek to enhance their effectiveness as workers. When these needs are at odds with one another, they become conflicting constraints that inhibit individual need satisfaction. Order emerges from interaction around these constraints resulting in compromises among individual need preferences (the correlation phenomenon).

We refer to this dynamic as first-order behavior because it involves resolution of conflicting constraints among the constituent units of an organization. Correlation also occurs on another level, which we will call second-order correlation. First-order correlations accommodates not only the needs of individuals, it also accommodates the needs of the network (aggregate) as a whole; that is, the correlational process seeks to maximize the first-order fitness needs of each individual and the second-order fitness-need of the aggregate. Resolution of problems between two departments, for example, will truly be resolved only if it is consistent with the fitness of the larger organization. Neither the individual nor the aggregate receives everything it would selfishly want, thus, fitness is not maximized absolutely. Rather, fitness is maximized to the extent that it can, given the compromises that must be made to achieve fitness.

Such a fitness maximization leads to nondeliberate control of the system's present and future: a nonteleological teleology, so to speak. Teleology is defined as the deliberate pursuit of a desired end. Complexity theory suggests that systems pursue goals nondeliberatively - "as if moved by an invisible hand," to quote classical economist Adam Smith (Smith, 1799). The result is nonteleological in that the system achieves its first- and second-order needs without global coordination; indeed, according to complexity theorists, it achieves a fitter future than could be achieved from top-down efforts. It is teleological in that this nondeliberative process is focused on creating a fit future.

Physics refers to the external and internal demands and restrictions that limit or enable system behaviors. Physical restrictions may include limitations imposed by technology, by the availability of resources, by size and coordination, and by organizational or social inertia. Conflicting constraints imposed by differing firstand second-order needs can be subsumed under physics. The demands can be restricted by an organization's mission. Physical demands can even be socially constructed, reflecting social beliefs rather than technological reality (DiMaggio \& Powell, 1983; Scott, 1987). Solutions that emerge out of need-driven autocatalytic activity are restrained by physical conditions and (more importantly) are shaped by the need to resolve interacting physical constraints. Conflicting need constraints, for example, impose barriers and challenges for the autocatalytic process. Complex leaders seek to control physical restraints by, among other things, 
identifying and acquiring enabling technologies and other resources or by "dropping" ideas into the system.

Natural selection helps drive the selection of forms from among sets of possible forms ${ }^{1}$ (as restricted by physics). Selection proponents further argue that mutations provide the variation from which selection chooses. Complexity theorists see a role for mutation, but argue that mutations alone are not nearly sufficiently powerful to generate the diversity observable in the biological and social world. Kauffman (1993), for example, provides convincing evidence that accident associated with mutation has not had sufficient time on this planet to create even a small portion of the complexity that exists. Mutation and selection are important in complexity theory, but they cannot stand by themselves.

\subsection{Emergence}

The microdynamics of complexity interact with complex natural teleology (i.e., macro-) dynamics to create emergence. Emergence begins with the creation of small groups (see Figure 1 above). These groups are labeled "aggregates," a term borrowed from John Holland (Holland, 1995) who coined it to refer to structures that emerged in his neural network computer simulations. Applied to social systems, aggregates are small groups of directly interacting actors who have a sense of common identity. An aggregate might be a family unit, a social clique, or a work group. Aggregates are limited in size because of the need to work out conflicting constraints among themselves - if too large, there would be too many conflicting constraints to work through and common identity, or order, could not emerge. The system would be forever trying to accommodate its conflicting constraints and never finding solutions. In the context of complex natural teleology, size, then, is a physical restraint.

Aggregates interact with other aggregates to form meta-aggregates (again borrowing from Holland, 1995). Meta-aggregates are defined as clusters of aggregates that are somewhat less interdependent and directly related than are the units in an aggregate, but which are linked by direct dependence on common resources or events. An organization's clients, its suppliers, and its external board of directors are all elements of a meta-aggregate. Meta-aggregates, like aggregates, are limited in size by the necessity to work through conflicting constraints.

Aggregation and emergence in general is influenced by, and influences, coupling patterns among and within aggregates. Members of aggregates are linked in vast networks of couplings. The average coupling pattern tends to be moderately strong for quite practical reasons: overly strong couplings would present too many conflicting constraints to be resolved, and excessively weak couplings would present so few conflicting constrains that there is little incentive to develop aggregate fitness. Kauffman (1993) identifies this moderately coupled network as complex. Indeed, moderate coupling is a signature definition in complexity theory.

\footnotetext{
${ }^{1}$ Selection is not the only force that determines survival, however. Evidence suggests that initial advantage (being there first with the most) plays an important role in survival - that is, the best do not always prevail (cf. Waldrop, 1992).
} 
Moderate coupling describes an average state of the system; actual patterns within the complex system vary from relatively tight to relatively loose (Kauffman, 1993). Tightness permits an organization to resist small to moderately strong environmental perturbations, but when change does find its way into such a system, it spreads rapidly. Looseness permits localized adaptations to environmental perturbations, but such subsystems resist system-wide change. Looseness can be frustrating for an administrator who is attempting to implement change. Even so, such structures are important for two reasons: (1) they allow local adaptations (Weick, 1976, 1979, likewise observed this benefit in his treatment of loosely coupled systems) and (2) looseness allows some systems to weather rampant, damaging change, as when there is a significant downturn in market conditions.

Aggregation and meta-aggregation, driven by the engines of correlation and complex natural teleology, are fertile environments for the emergence and diffusion of such things as innovation, ideas, cooperation, fitness, even extinction. Localized members of an aggregate are stimulated to spawn innovations, for example, by the correlation, spontaneity, competitive tension, autocatalytic dynamics, need, and physics that characterize moderately coupled systems. The network further enables (but does not ensure) opportunity for diffusion (moderately coupled networks can "trap" the spread of innovation as easily as they enable it). Moderately coupled systems do something more, however: they provide an ambiance in which separate, otherwise isolated innovations can interact and, like the social systems that created them, form innovative aggregates and meta-aggregates.

The separate pieces of today's microcomputers, for example, emerged individually during the first two-thirds of the 20th century. Slowly, these independent pieces began to find one another and form higher-order innovations, such as transistor radios, television sets, dumb terminals, hand-held calculators, and intelligent toys. Then, in 1975, the meta-aggregates found one another and the desktop computer emerged - seemingly without history but in reality with a rich pedigree.

All this results from bottom-up rather than top-down dynamics. Top-down coordination refers to coordination by a central authority; bottom-up refers to emergent events that occur because of normal, uncoordinated interaction among constituent units. McKelvey (1999), referencing theorist Yaneer Bar-Yam, has said that, when an individual controls group behavior, the group behavior can be no more complex than that individual. That is, top-down control leads to relatively unsophisticated innovations and fitness. McKelvey (in press) rejects traditional images of heroic, visionary leaders charging ahead of their workers to lead them to productive utopia. He and complexity theorists in general argue that the greatest creativity, productivity, and innovation comes out of people who are provided opportunities to innovate and network - the bottom-up principle. The complex of individuals, aggregates, and meta-aggregates, networked together by convoluted, multiple but moderately coupled chains of interdependencies and driven by correlation and complex natural teleology, are beyond individual control and can produce far more than a single individual would ever be capable of or could even envision.

Finally, many changes in complex systems emerge precipitously, or rather they appear to do so. This is the nonlinear characteristic of Complex systems. Aggregates and meta-aggregates build slowly at first-microcomputers, for example, were 40 
or more years emerging. At some point, a critical mass occurs, emergence speeds up and something becomes inevitable. Very shortly following that, the pieces come together precipitously - as if overnight. An innovation seems to appear out of nowhere, but of course it does not. Much construction goes on behind the scene before the pieces collapse together, and the change only seems to be precipitous.

The fall of the USSR in 1989 appeared to come out of nowhere, but the pieces - a strained economy, the pressures of competing with Western economies, difficulties with satellite states - had been evolving for decades. The collapse was the culmination of all this, and more. One can decrease elementary school classes to 30, 26, then 23 without appreciable impact on achievement, but a decrease to around 18 students will tend to produce a significant improvement in average scores (Ferguson, 1991). It is the camel and straw phenomenon. Systems are sufficiently robust, because of their interlocking networks and moderate coupling patterns, to suffer perturbation after perturbation without outward signs of change. At some point, however, the networks become overwhelmed with one more perturbation and the existing system collapses. With emergence (as opposed to collapse), pieces come together slowly, networks build into networks of networks, and at some point the meta-aggregates collapse together to create seemingly precipitous change.

In summary, complexity theory argues that organizational structure and behavior are, on the one hand, products of random surprise and nonlinearity, and, on the other hand, products of the unifying effect of correlation. It is inaccurate to define these forces as polar opposites, although it is accurate to say that they create tension within a system. Rather, like two people who bring different skills to a task, these seemingly opposing dynamics work together to create emergence. Random behavior and nonlinearity provide creative surprises, they apply pressure that creates conflicting constraints, and they are actors in the dynamic that enables different pieces of order to accumulate, interact, and collapse together. Correlation, in turn, provides the structure against which conflicting constraints are arbitrated and organization is built.

These forces drive, and are driven by, autocatalysis, need, physics, and natural selection-complex natural teleology. They foster an ambiance of nonlinear behavior and moderate coupling. Together, correlation and unpredictable behavior, complex natural teleology, and the resulting ambiance, foster the emergence of order, fitness, innovation, and growth of an aggregate and meta-aggregate. Order emerges unbidden, requiring little or no outside work from natural selection or from top-down human planning, as if moved by an invisible hand.

\section{Leading in complex organizations}

How then, does the previous discussion relate to the study of leadership? We have already suggested some answers to this question, but will draw our observations together in this section.

To answer the question, we refer to the prescriptive/nonprescriptive debate in organizational theory over whether theorists can provide prescriptions for effective leadership behavior. Complexity theory would seem to favor nonprescription because of its bottom-up perspective. Complexity theory also suggests, however, that leadership theorists may be looking for the wrong solutions to or- 
ganizational control, that prescription and nonprescription incompletely frames the problem. They are looking to influence systems directly (or to contradict direct influence), to determine how to dictate future organizational states. They need, instead, to understand that the success or failure of leadership actions is attributable to the capacity of the organization that supports them. Their strategies and charismatic appeals are useless if they fail to foster conditions that enable productive, but largely unspecified, future states. They need to feed the natural, bottom-up dynamics of emergence, innovation, and fitness. They need to think broadly in terms of systems, of nonlinear effects, and of network forces. Leaders need to understand the patterns of complexity and learn to manipulate the situations of complexity more than its results.

That is where prescriptive theorists have slipped up, and it is what the nonprescriptive theorists have missed. Social systems are nonprescriptive in their detail but subject to prescription (in a general sense) in their broad, holistic behaviors. In other words, once the proper conditions are created for bottom-up dynamics, leaders need to leave the system alone to generate positive emergence (i.e., nonprescriptive in detail), yet still provide general control (i.e., broader goals/vision, refocusing network conditions) to keep the system generally (as opposed to specifically) focused and to maintain - and further enable-its complex structure.

The transformational leadership literature begins to address such behavior. Bass (1985) argues that transformational leadership (1) enhances follower awareness and acceptance of the organization's goals (i.e., broad direction), (2) encourages them to make their personal desires subservient to the needs of the organization or the team (i.e., a concept which facilitates correlation), and (3) activates their higher-order needs (i.e., the need described in complex natural teleology). According to Boal and Hooijberg (2001) and Schein (1992), effective leaders achieve transformation through the symbols they project, the way they respond to crises, by the way they model their expectations, in how they allocate rewards, and how they deal with selection and dismissal of personnel. Bennis and Nanus (1985) argued that transformational leaders develop a vision for the organization, develop commitment and trust among workers, and facilitate organizational learning.

Such perspectives are still limited, however, in that they assume that leaders directly control and determine future events with their actions. But what is the alternative? The question frames the problem, which assumes that the problem is one of opposite positions thus one or the other must be correct. We believe the question has been so encapsulated by the reductionist mindset of science that the alternative has been overlooked. The alternative is simple: to temper our focus on controlling organizations and futures and instead develop leaders' abilities to influence organizational behavior in ways that enhance the odds of productive futures.

For example, we need to think of social systems similar to leading neural networks. Neural networks are information-processing networks of interdependent actors. Just as thinking is a function of the brain's ability to create emergent networks among neurons (Kauffman, 1993; McKelvey, in press), organizational fitness is a function of the organization's ability to foster emergent networks among people. Complex neural networks are coordinated largely by bottom-up dynamics that function to resolve local conflicting constraints and obtain needed resources. The behaviors of neural networks have been tested extensively with 
computer simulation experiments. Computerized models are able to produce solutions to complex problems such as finding paths through complicated mazes or developing strategies for surviving in "hostile" environments (Levy, 1992).

Social systems function like neural networks in that they too are composed of interdependent, need-seeking actors. They process information and are highly efficient at solving social problems, creating fitness, and spawning innovations. The question we pose, then, is how does one lead a social "neural" network without interfering with the powerful, interactive, and bottom-up dynamics? How can leaders help such networks be optimally productive? Our answer is that they do it by enabling rather than controlling network dynamics.

We propose that theorists devote attention to influencing the nature of networks, the atmosphere for aggregate and meta-aggregate formation, and the ambiance for innovation and dissemination. We call it complex leadership, and base it on complexity thinking (Richardson \& Cilliers, 2001). Such thinking "involves a shift in philosophical thinking that might well put off practicing managers... If one assumes that organizations are indeed complex systems, ... a fundamental shift in the way sense is made of our surroundings is necessary" (pp. 7-8).

To illustrate how these concepts differ from leadership perspectives of the past, we describe below how complexity concepts apply to leadership practice and research. Our discussion is intended to highlight how complexity thinking might translate into activity. First, we provide some specific examples of how leadership roles are redefined, and then conclude with a discussion of implications for leadership study.

\subsection{Complex leadership}

\subsubsection{Foster network construction}

In complex organizations, effective leaders learn to manage and develop networks. They foster and cultivate interdependencies within and without the organization (Marion \& Bacon, 1999). As Regine and Lewin (Regine \& Lewin, 2000) concluded in their ethnographic study of leadership in a dozen US and UK industries that were operating according to complexity principles, "Leaders generally felt that it was their responsibility to enrich connections in the system - that is, to forge new connections where none existed or to improve existing connections" (p. 10). They build and tend to networks at the aggregate, meta-aggregate, and meta-meta-aggregate levels - the interactive fingers of the effective organization should spread wide and far.

Networks are, of course, important because of the contacts they provide, but if this were all then complexity would have little to offer. It is the network itself, more than direct gain from a relationship, that benefits network participants. Networks provide the structure within which innovation can emerge and grow, as we discussed earlier. Systems within a network feed one another both directly (suppliers and buyers, for example) and indirectly (body shops provide services that help make the automotive industry viable, for example). In addition, networks are a source of strength and fitness. A strong network can provide almost invincible fitness to the technologies around which it is constructed; by extension, it provides fitness to its participating systems as well. Networks resist usurpation because of the strength of their interactive commitments. 


\subsubsection{Catalyze bottom-up network construction}

Complex leaders will not only build networks (Gnyawali \& Madhavan, 2001), they will help catalyze network-building as well. A catalyst is a person who indirectly fosters network construction (Levin, 1993). The leader can perform this role through delegation, by providing encouragement and resources to subordinates (such as enabling workers to attend conferences), or by simply not interfering in network construction (Marion \& Bacon, 1999). Leaders could extend decision-making powers to their staff, and trust (plus expect) them to utilize the responsibility well (Manz \& Sims, 1984). They could organize their work environment to enable and encourage interaction among workers (cubicles can encourage isolation; complex leaders structure open spaces or organize offices around a central work area). Complex leaders build rituals and myths that are oriented toward interaction and networking (Schein, 1992). They avoid solving problems for workers; instead, they require that they work out their problems together (Manz \& Sims, 1987). They move quickly to get personal conflicts resolved but enable, even encourage, task-related conflicts which resolve conflicting constraints (Jehn, 1997). They encourage communication among the components of their aggregates, meta-aggregates, and meta-meta-aggregates.

\subsubsection{Become leadership "tags"}

Leaders also catalyze network development by becoming what John Holland (Holland, 1995) has called a "tag." As we said earlier, a tag symbolizes the aggregate and it separates an aggregate from other aggregates. It is the flag around which everyone rallies; it is the philosophy that binds people together.

Tags are not necessarily leaders. Flags and ideas do not lead, they symbolize and draw people together. Leaders can be potent in the role of tag, however. The catalyzing school principal might serve as a tag for instructional excellence; the catalyzing dean might serve as tag for a school's research excellence and its teaching reputation. Such tags articulate a system's personality for its inhabitants and for its public. They rally subordinates around the organization's ideals. They build myths that implant the system's ideals into the minds of workers and the public. Leadership tags can embody the organization within their own personalities, much as Howard Hughes embodied the essence of Hughes' Aircraft with his personality. The tag becomes the organization and the organization becomes the tag - they are inseparable and unique, well defined against a background of other systems.

Tags promote and articulate an idea and an attitude. But they do not necessarily control the movement as many charismatic writers want to suggest (Howell \& Frost, 1989; Kirkpatrick \& Locke, 1996). Indeed, in many ways, they are simply along for an inevitable ride. Movements and organizational systems are complex entities, and the wise leaders will not stifle their creativity with strict, top-down controls.

\subsubsection{Drop seeds of emergence}

Leaders of complex organizations drop seeds of emergence. McKelvey (1999, p. 77) poses the question, "How do we actually do leadership in a way that fosters emergent structure in a firm without the leader somehow creating a bunch of passive followers following some vision?" (p. 77). They do it by identifying 
knowledge centers within an organization, by encouraging the centers to do creative things, and by getting them to communicate with one another. Leaders encourage people to try things, then to evaluate and change their experiments (Allen, 2001). The complex leader does not closely control, for controls limit the organization's potential; rather, the complex leader creates organized disorder in which dynamic things happen at multiple locales within the system (Regine \& Lewin, 2000).

Such a leader seeks to spawn emergent behavior and creative surprises rather than to specify and control organizational activities. Complex leaders help workers develop "solutions without problems" (Cohen \& March, 1974; Cohen, March, \& Olsen, 1972, 1976) by sending them to conferences or similar idea spawning activities. And they foster the development of moderately coupled structures in which ideas can emerge freely and find one another.

\subsubsection{Think systematically}

Complex leaders think systemically (Senge, 1990); they are aware of the interactive dynamics going on at the aggregate, meta-aggregate, and meta-meta-aggregate levels. This is not an easy thing for most of us to do-as leaders or in our personal lives. We interpret situations in terms of the things that are happening to us immediately and fail to see the larger picture (this argument is the thrust of Senge's observations) (Senge, 1990), consequently, we move from one localized incident to the next stamping out the fires but never seeing the broader pattern of events. We perceive problems as events that happen to us and fail to understand that we are part of the network of events that created the problem. There is pattern to complex systems, but we often cannot see it because we are too focused on our immediate experiences. Learning to see the systemic whole can be revelatory.

In sum, complex leadership should be viewed as creating conditions that enable the interactions through which the behaviors and direction of organizational systems emerge. Leaders provide control by influencing organizational behavior through managing networks and interactions. They do not delude themselves with the notion that they can determine or direct exactly what will happen within the organization. The dynamics of interaction, guided by complex leaders, help the organization develop appropriate structure, innovation, and fitness.

A question that arises, however, is related to fundamental needs for control. If complex leaders are influencing rather than controlling, how can organizations function? For example, many managers need to spend considerable time controlling (e.g., dealing with problem employees, enforcing rules and regulations, etc.) to enable the organization to survive. How does this fit within the framework of complex leadership?

Part of the answer to this question lies in the distinction between leadership and management. Leadership can be roughly defined for our purposes as tending to growth, fitness, innovation, and the future of organizations. Management is tending to the nuts and bolts of detailed operations. Such role definitions are not new, but researchers and practitioners are not always careful to distinguish between them. The relevance for this discussion is that certain positions and levels within the organization will require leadership, including complex leadership, while in others management may suffice. Though complex leadership is desirable throughout organizations, similar to Hunt's (1991) and Jaques' (Jacobs \& Jaques, 
1987; Jaques, 1990) findings we argue that complex leaders will be needed at levels where the decisions they make address longer time spans of responsibility, the situations facing them are more complex, and their positions make them directly responsible for the innovation, growth, and fitness of the organization. For example, leaders who are higher in the managerial hierarchy are more focused on environmental relationships and with fitness and growth than are mid- or lower level administrators.

Moreover, the need for complex leaders will vary depending on the type of organization and environment in which it operates. Cohen et al.'s (1976) discussion of hierarchical structure, specialized organizations, and organized anarchies may be useful here. Hierarchical structures are highly routinized and stable; from the perspective of complexity theory, they are mature organizations in a mature technological environment, and have few concerns about fitness and growth. Organized anarchies, by contrast, exist in more volatile environments and are significantly concerned about fitness and growth. The latter would require complex leadership more than the former; specialized organizations lie between hierarchical structures and organized anarchies, thus, they demand only moderate levels of complexity thinking.

The need for complexity thinking is also influenced by the degree of interaction within a market (this is related to the volatility issue above) and to the cost of change (equipment used by auto manufacturers is very expensive, for example, and cannot be changed on a whim). Volatile environments demand complexity thinking, but expensive industries require stable technologies and hierarchical structures where complexity thinking is not particularly desirable.

\subsection{Theoretical implications}

Our discussion of complex leadership also links to emerging trends in the leadership literature (e.g., social capital, self-leadership/empowerment, followership, transformational, and charismatic leadership). Social scientists are beginning to recognize the need to examine behavioral systems from broader and more integrated perspectives such as those represented by complexity (Hunt \& Dodge, 2000; Hunt \& Ropo, in press). While these varying trends relate to complexity notions, they have not yet been linked to them. Drawing from the example earlier about emergence and innovation in the computer industry, the parts (e.g., emerging theoretical thrusts) are beginning to interact with the complexity thesis but they need to find one another and form higher-order innovations. The discussion below is intended to help spark this process by showing how these approaches link to complexity theory, and how complexity theory can refine our understanding of the way we need to think about these trends.

\subsubsection{Social capital/social exchange/relational approaches}

One such trend is the growing interest in social capital (Coleman, 1988; Leana \& Van Buren, 1999), social exchange (Masterson, 2000; Settoon, Bennett, \& Liden, 1996), and relational leadership (Graen \& Uhl-Bien, 1995; Uhl-Bien, Graen, \& Scandura, 2000). These approaches all discuss the importance of interactions among individuals, with social capital addressing it from macrolevel or systems perspectives (Nahapiet \& Ghoshal, 1998) and social exchange and relational lead- 
ership addressing microlevel, or dyadic and small group, exchanges (Uhl-Bien et al., 2000). Taken together, these theories address networks of relationships (Leana \& Rousseau, 2000) and the importance of linkages among individuals (Graen \& Uhl-Bien, 1995).

Social exchange and relational leadership address the generation of effective work relationships through dyadic relationship building (Uhl-Bien et al., 2000). Such relationships are tied to production of outcomes that are necessary for organizational functioning (Gerstner \& Day, 1997). Social capital represents assets embedded in relationships that contribute to the creation of valued outcomes (Coleman, 1988; Leana \& Van Buren, 1999). It acknowledges that innovation comes when organizational members effectively convey their individual capabilities through interactions with others. Consistent with fundamental complexity concepts, social capital theory is beginning to focus on the network itself, addressing network effects on organizational systems and network participants. For example, Dess and Shaw (2001) describe how networks of ties among organizational participants may generate innovation that could be lost if network member(s) leave and disrupt the system dynamics or take other key network members with them.

Complexity theory describes how networks of interaction enhance the potency of resource exchanges beyond their individual or summed values to the network, and how the interaction of resources add strength and vibrancy to the system as a whole (meta- or meta-meta-aggregate). At the microlevel, complexity theory addresses interaction and correlation, concepts that may be related to social exchange and relational approaches. At the macrolevel, complexity theory can direct social capital theory to questions that could extend its contributions to understanding. For example, contrary to Dess and Shaw (2001) who assert that network losses affect innovation and productivity; complexity theory predicts that robust complex networks resist damage from such loss.

Applying complexity thinking, Dess and Shaw's (2001) work could be expanded to discuss whether the nature of networks as described by complexity theory would affect the propositions these authors set forth. In general, complexity theory describes how network interaction creates organizational fitness and innovation; it describes the dynamics that lead to emergence and to failure. They describe the ambiance against which social capital exchanges occur. This skirts very close to questions that social capital theorists are exploring, particularly their questions about network interactions and organizational fitness.

\subsubsection{Self-leadership/empowerment}

In the past several decades, self-leadership perspectives have achieved prominence among the leadership theories (Hackman, 1986; Manz \& Sims, 1984, 1987). These approaches emphasize the importance of a reduced role of leadership control and increased need for authority and responsibility to be delegated downward in organizational hierarchies (Walton, 1985). Advocates of these approaches identify the role of the leader more as coordination and coaching than directing and supervising (Manz \& Sims, 1987), and focus on follower empowerment and self-management (Thomas \& Velthouse, 1990). These arguments are closely related to the bottom-up thesis in complexity theory, the idea that robust, complex networks coordinated by bottom-up coordination and interaction are capable of far greater fitness and creativity than are top-down, leader-controlled systems. 
Again, complexity theory can expand this perspective (empowerment) by suggesting new areas of endeavor. For example, it might be productive to explore the impact of moderately coupled networks on empowered work groups, or the relation of empowered work groups to emergence and fitness. Decentralized businesses offer a ripe laboratory for studying the optimal conditions for emergence. Taking cues from critical theorists, one could explore the degree to which leaders actually do relinquish power in decentralized organizations, and the manner in which subtle control strategies (such as manipulation of the reward structures; see Ezzamel \& Willmott, 1998) affect emergence and innovation.

\subsubsection{Followership}

Though not a prominent body of research, interest is increasing in issues of followership (Ehrhart \& Klein, 2001). Researchers are discussing leadership as a two-way exchange in which followers are integral to the leadership process (UhlBien et al., 2000); however, research has not yet adequately explored the role of followers in leadership processes. The bottom-up principle in complexity theory suggests that follower behavior may be critical for structure and fitness in systems. It may also suggest a different way to consider the effect of follower behavior within organizations. We propose that issues of follower behavior need to be more fully examined in the leadership literature, and that complexity theory may provide some help in doing so. We might, for example, explore the relationship between networks and the diffusion (correlation) of followership behaviors. How do emergent follower behaviors influence leadership activities? Do complex leadership strategies - such as dropping seeds of innovation or catalyzing bottom-up coordination-change followership patterns of behavior? In what ways do these strategies affect follower expectations of leadership?

\subsubsection{Transformational leadership}

The link between transformational leadership and complexity has been hinted at throughout this paper. Transformational leadership addresses multiple issues that are related to the complexity principle of correlation. Transformational leaders provide the language, symbols, and emphasis on mutual goals that can help lead to correlation (Bass, 1985; Hater \& Bass, 1988). They also lead followers to compromise their personal needs in order to accommodate the needs of others (Bass, 1985), which is a defining characteristic of correlation. Moreover, transformational leaders encourage followers to question ideas and assume responsibility (e.g., delegating and empowering) because they show confidence in followers' ability to take on assignments. This represents a facilitating rather than controlling leadership style.

Complexity theory suggests that transformation (emergence) occurs bottomup and is enhanced by moderately coupled interaction patterns. The very fact that transformation is emergent as opposed to created (the latter being a top-down process) has important implications for the role of transformational leaders. In a sense, we refocus transformation theory away from analysis of relationships between direct leadership behavior and organizational outcome to analysis of the relationship between transformational environments and fitness and the role of leadership in catalyzing (as opposed to creating) such environments. We call this complex leadership. Researchers might want to explore the nature of network dy- 
namics that accompanies transformation, or to explore how leadership behavior affects those dynamics. They might examine the nature of control versus enabling in networks that are transformational. They could look for the events that collapse together to create transformation and describe how transformation emerged. Toward this end, researchers might incorporate elements of social exchange theory and followership with complexity and transformation to create a meta-aggregate explanation of transformation.

\subsubsection{Charisma}

There is a rather obvious-and, we feel, interesting-relationship between complexity theory's concept of the tag and the concept of charismatic leadership. As we stated earlier, complex systems totter on the edge of chaos, sufficiently active to be dynamic but not so active they risk continual disruption. Major change occurs when they step over that edge to a dramatically different fitness strategy. At times, such change can result from emergence and the activities of tags. That is, systems are capable of producing structures (the tag) that may perturb and alter the very system that produced it.

Charismatic leaders are described as having the ability to formulate and articulate an inspirational vision (Conger, Kanungo, Menon, \& Mather, 1997). They exhibit behaviors and actions that foster the impression that they and their mission are extraordinary in such a way that they get others to rally around them (Pillai \& Meindl, 1998). Like tags, charismatic leaders have been described as change agents.

Complexity theory could be quite useful in helping us expand our understanding of the charismatic dynamic. It could help us better understand how charismatic leaders emerge or the conditions under which charisma is fostered. One might explore whether charisma is more likely when network connections tighten and systems approach a chaotic state (i.e., approach close to the edge of chaos). Complexity theory might suggest research on the relationship between network dynamics (particularly those related to emergence, diffusion, and innovation) and the success of charismatic leaders. We could ask whether charisma encourages or suppresses further innovation or locks the system into the vision articulated by the charismatic. One could look in general at the collateral systemic activities that accompany charismatic dynamics, such as innovation, communication patterns, aggregation, and bottom-up activity. It may very well be, for example, that leaders significantly alter, even curb, normal complex dynamics.

\section{Research strategies}

Our intent in this section is to outline a simplified structure for studying complex leadership, to examine possible strategies for evaluating complex systems, and to suggest research topics that might arise out of our designs. In doing so, we contribute to the evolving process of moving complexity study from the arena of metaphor to that of science and we operationalize the basic premises underlying complexity theory (as outlined in earlier sections). We do not seek to present a mature and full discussion of complex research, for that is a separate topic in and of itself, and is not appropriate within the context of this article. Rather, we will 
develop only what is needed to support the complexity thesis and to suggest possibilities for pursuing our conclusions further.

Traditional statistical research can be broadly represented either as a probabilistic relationship between (1) an ensemble's, or aggregate's, initially measured conditions and its final or outcome state or (2) the states of two separate aggregates. We define an aggregate for traditional probability studies as a set of individuals, each of whom are defined relative to a given variable or variables (e.g., intelligence, attitude, consideration behavior) and located within the normally distributed domain of values for that variable. For complexity research, we add that an aggregate is composed of individuals whose behaviors are correlated because of a primary interdependency, such as that found in a family or a work group. We label the aggregate " $\rho$. " In one important form of statistical research strategy, the probabilistic distribution of individuals is measured at $t=0$ (its initial state, $\rho_{0}$ ) and again at some later point in time (labeled $\rho_{1}$ ). The distribution of individuals within $\rho_{0}$ is then compared to that of $\rho_{1}$. This can be described with the equation, $f\left(\rho_{0}\right)=\rho_{0}$, where $f$ is typically expressed as a probability correlation.

The structure of complexity research is similar to this traditional research strategy, but it must be conceptualized differently. Specifically, we need to understand the relationship between $\rho_{0}$ and $\rho_{1}$ in terms of mapping: $\rho_{0}$ maps onto $\rho_{1}$ (see Figure 2). Such mapping is denoted as $\rho_{0} \rightarrow \rho_{1}$, and indicates that each individual in $\rho_{0}$ moves over time to a new location in $\rho_{1}$. Mapping focus attention on dynamical movement, which is foundational to complexity theory, but does so with measurements at discrete points in time rather than with continuous measures. To analyze maps, one analyzes the distribution of individuals in $\rho_{1}$.

Complexity research, like statistical analyses, accounts for the transition of $\rho_{0}$ into $\rho_{1}$; but complexity also allows for interaction among aggregates. Omnès (1999) has decomposed system behavior into (a) the behavior of relevant internal variables, which he labeled $H_{c}$ (where $H$ is a Hamiltonian - a measure of energy in a dynamic system), (b) the behavior of pertinent environmental variables $\left(H_{\mathrm{e}}\right)$, and (c) a coupling variable $H_{1}$ that reflects how internal variables affect, or are affected by, environmental variables. That is, total behavior $H=H_{c}+H_{e}+H_{1}$. If a focal aggregate $\rho_{0}$ interacted with one other aggregate $\rho_{a^{\prime}}$ for example, then one's research design could be represented as follows (Figure 3 ), in which total behavior $\rho_{1}$ is a product of its initial conditions $\rho_{0}$ (which could be measured on several variable dimensions) and its interaction with environmental aggregate $\rho_{\mathrm{a}}$.

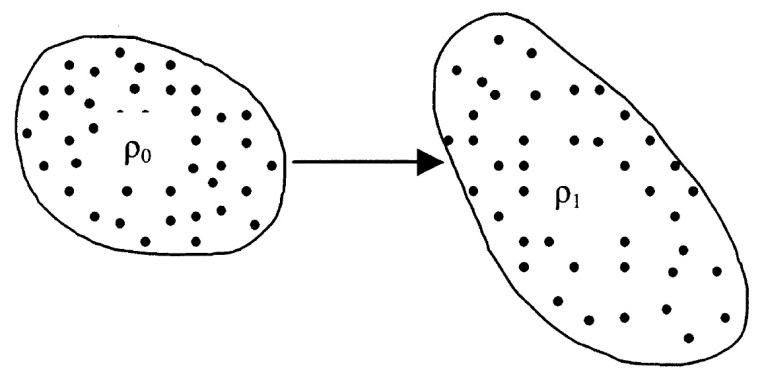

Figure 2. Mapping of ensemble $\rho_{0}$ to ensemble $\rho_{1}$. The distribution in $\rho_{0}$ becomes the distribution in $\rho_{1}$ after some period of time and, as appropriate, after some intervention. 


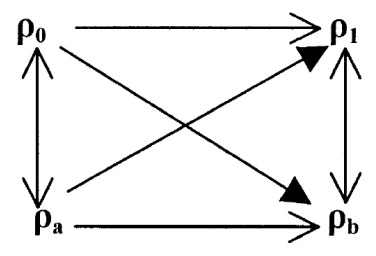

Figure 3. Research design representing the interaction of $\rho_{0}$ and $\rho_{\mathrm{a}}$ in the production of $\rho_{1}$.

Here, $\rho_{1}$ is mapped from $\rho_{0}$. Further, $\rho_{0}$ and $\rho_{1}$ are functions of two-way interaction with second aggregate, which itself evolves over time from $\rho_{\mathrm{a}}$ to $\rho_{\mathrm{b}}$. Aggregate $\rho_{0}$ influences the initial state of aggregate $\rho_{\mathrm{a}}$ (assuming it has a previous history with $\rho_{\mathrm{a}}$ ) and it affects its final state - and vice versa.

Two important observations derive from this design. First, $\rho_{0}$ interacts with other aggregates like $\rho_{\mathrm{a}}$. Standard statistical designs evaluate interaction with other variables; complex research also evaluates interaction with other aggregates. Different variables describe different characteristics of the same aggregate (a description of its average socioeconomic status, for example). Different aggregates, by contrast, represent different sets of individuals.

Second, the design focuses not only on the evolution of a target aggregate, it focuses on the evolution of interaction patterns among aggregates as well; that is, it focuses on the emergence of meta-aggregates. The researcher might observe an initially weak influence between the two aggregates turn into a moderately strong relationship, or one might observe an initially strong relationship moderate over time. Kauffman (1993), for example, observed that strong inter-influence among initially emerging, computer simulated networks tended to moderate over time. He concluded that tightly interacting aggregates are unstable (which is conducive to rapid early development), but that mature networks required more moderate, less chaotic, interactions in order to achieve fit states (see Marion, 1999 for a discussion within the context of social systems).

There are several possible ways to evaluate such a structure. Traditional multivariate path, or causal, designs are suggested by Figure 3, for example. Using this figure, two complex aggregates might be measured on a single variable (such as attitudes regarding locus of control). Both the initial and final states of the target aggregate are causal outcomes of attitudes in the second aggregate; further the final state of the target aggregate is a function of its initial state. Results would indicate the degree to which the target aggregate's final state is a product of (a) its initial state and (b) the actions of the second aggregate.

There are significant limitations to this approach, however. It may be difficult to show an interactive (as opposed to outcome) effect, for example. Further, the design does not address the emergent relationship between the two aggregates. More importantly, however, the strategy does not adequately deal with issues of history. Gell-Mann (1994) calls this "course graining," in which "interference" is assumed to be randomized and is, consequently, summed over. This ignores the history of the aggregates and the unexplained variance likely relates to an important part of that history. The heights of 10-year-old pine trees in a forest vary in part because of variations in the sunlight and moisture each has received 
over time. Course grained evaluations measure these variables at a single point in time, ignoring the historical variations and assuming that the single measure is an adequate summary of the history.

Course graining can be addressed with at least two strategies. The first strategy is to model social dynamics with computer simulations. Carley and Ren (2001), for example, have modeled interactions among personnel, resources, and tasks in an organization, and have confirmed their observations with qualitative research strategies. Data used in this simulation included span of control (average number of agents who report to one another), resource load (average number of resources assigned to one agent), and need for negotiation (the extent of negotiation over resource access). In this example, aggregates are labeled agents, referring to interacting personnel or subgroups within an organization.

Finally, complex dynamics can be studied with traditional ethnographic procedures (see also Hunt \& Ropo, in press). Ethnography would permit analyses of complex interactions and behaviors that may be beyond the capacity of a quantitative or simulation approach. Figure 3, as presented, represents a somewhat simplified view of reality, one that can be corrected by qualitative analysis: it does not reflect the "'joining' (sic) of multiply subjectivities - multiple dimensions interacting with overlapping but not identical multiple dimensions" (Allen, 2001, p. 27).

That is, reality cannot be accurately represented as a flowchart composed of unique and separable activities or groups, but qualitative analysis can easily handle such messiness. Qualitative researchers could evaluate the emergence of subaggregates within a given aggregate or of meta-structures among aggregates. One could easily evaluate interactions among multiple groups, observe the temporal behaviors of systems of aggregates and collect data on the histories of those systems (fine grain analysis), and evaluate nuances of the emergent process. Indeed, qualitative researchers do these sorts of things already; the only difference is our proposal that a complexity superstructure be added to guide research.

We envision three types of general research design for this structure. First, as we have already alluded, the structure could be analyzed with computer simulations, much as Carley and Ren (2001) have done, or with mathematical simulations, such as that developed by Peter Allen (Allen, 2001). The intent would be to provide evidence to support or contradict theoretical premises in a controllable environment. Such strategy permits the study of massive networks of interaction - a prohibitive task in actual social research.

Second, our research structure could be developed within the context of experimental simulations, as developed by Arrow, McGrath, and Berdahl (2001) (for further discussion, see Hunt \& Ropo, in press and Ilgen \& Hulin, 2000). This involves controlled simulations with small groups. One might, for example, create a laboratory situation in which several groups try to solve different parts of a cooperative task (some parts could be closely interdependent and others only loosely interdependent, for example). The researcher would collect data on the initial and final states of the groups and on the interaction patterns among the groups. The third design proposal involves qualitative strategies. With qualitative strategies, one can explore the nature of aggregation and observe it change-split, recombine, develop increased layers of complexity - over time. Thus, qualitative procedures are applicable to virtually any real life, field situation. 
Any of a number of leadership questions could be addressed with these strategies. Patterns of emergence could be examined with or without effective leadership or with different styles of leadership (tags), tasks could set up to be highly competitive, or the effect of different group sizes or coupling patterns on network emergence could be observed. Researchers could examine the impact of increased correlation among aggregates (as would be expected in situations with charismatic leaders) on innovation and dissemination, or could explore the effect of coupling patterns on innovation and dissemination. The dynamics of extinction could be explored - the extinction of innovations or of aggregates themselves. Researchers could examine the impact of a number of contingency factors, such as formalization, centralization, or raw materials. One could revisit the liability of newness problem from population ecology theory to determine what effect new systems exert on existing networks (see, for example, Brüderl \& Schüssler, 1990; Singh, Tucker, \& House, 1986). That is, the design can be useful for revisiting a number of existing questions in the theoretical literature using a complexity perspective, and for examining questions suggested by complexity theory itself.

\section{Conclusions}

Our interest in this article is in how complexity theory helps us understand the emergence of structure, fitness, and innovation in organization, and how emergence is influenced by leadership behavior. That is, we have explored what we earlier referred to as complexity thinking. Emergence is enabled by vibrancy, by systems that have built-in tendencies to change and the capacity to retain information about their changes - just the sort of vibrancy that is available in moderately coupled systems. The tendency to change derives in part from the individualist residues of correlation (individuals do not correlate all their resonance) and memory derives from the stable states that emerge out of correlation. Innovation and its diffusion are enabled by aggregation and network, the result of correlation and complex natural teleology within moderately coupled networks. Moderately coupled networks are sufficiently loose to enable vibrancy for generating innovation and sufficiently tight to permit different innovations to find one another, correlate, and form higher order innovations.

Complexity theory suggests that leaders must deal with the conditions of organizational activities more than their local manifestations. It suggests that we create transformational environments, or the conditions necessary for innovation, rather than creating the innovation itself. Complex leaders drop seeds of innovation rather than mandating innovation plans; they create opportunities to interact rather than creating isolated and controlled work cubicles; they tend networks; they catalyze more than they control. Complex leaders are tags, symbols, rather than brave ship captains guiding their vessels to port. Leaders are part of a dynamic rather than being the dynamic itself. Leaders are one element of an interactive network that is far bigger than they. Complex leaders can perceive those networks; they can help enable useful behaviors, including the expansion and complexification of the networks. They cannot, however, control those networks. 
Because of this, we believe complexity thinking provides a unique perspective by which to view leadership. We suggest that future research continue to build on the concepts introduced in this and other papers addressing concepts of leadership in complex systems (e.g., McKelvey, in press; Regine \& Lewin, 2000) so that we can more fully understand how complexity theory can inform leadership.

\section{References}

Allen, P., 2001. What is complexity science? Knowledge of the limits to knowledge. Emergence: A Journal of Complexity Issues in Organizations and Management 3 1, pp. 24-44.

Arrow, H., McGrath, J. E., and Berdahl, J. L., 2001. Small groups as complex systems, Sage, Thousand Oaks, CA.

Bak, P., 1996. How nature works, Copernicus, New York.

Bass, B. M., 1985. Leadership and performance beyond expectations, Free Press, New York.

Bennis, W. and Nanus, B., 1985. Leaders: the strategies for taking charge, Harper and Row, New York.

Boal, K. and Hooijberg, R., 2001. Strategic leadership research: moving on. Leadership Quarterly Yearly Review of Leadership 11 4, pp. 515-549.

Brüderl, J. and Schüssler, R., 1990. Organizational mortality: the liabilities of newness and adolescence. Administrative Science Quarterly 35 3, pp. 530-547 September.

Bryman, A., 1992. Charisma and leadership in organizations, Sage, London.

Carley, K., \& Ren, Y. (2001). Tradeoffs between performance and adaptability for $\mathrm{C}^{3} \mathrm{I}$ architectures. Part of the A2C2 project supported in part by the Office of Naval Research, Carnegie Mellon University.

Cartwright, T. J., 1991. Planning and chaos theory. Journal of the American Planning Association 57 1, pp. 44-56.

Cohen, M. D. and March, J. G., 1974. Leadership and ambiguity: the American college president, McGraw-Hill, New York.

Cohen, M. D., March, J. G. and Olsen, J. P., 1972. A garbage can model of organizational choice. Administrative Science Quarterly 17, pp. 1-25.

Cohen, M. D., March, J. G. and Olsen, J. P., 1976. Ambiguity and choice in organizations, Universitetforlaget, Bergen.

Coleman, J. S., 1988. Social capital in the creation of human capital. American Journal of Sociology 94, pp. 95-120.

Conger, J., Kanungo, R., Menon, S., and Mather, P., 1997. Measuring charisma: dimensionality and validity of the Conger-Kanungo scale of charismatic leadership. Canadian Journal of Administrative Sciences 14 3, pp. 290-302.

Cronbach, L. J., 1988. Playing with chaos. Educational Researcher 17 6, pp. 46-49.

Dess, G. and Shaw, J., 2001. Voluntary turnover, social capital, and organizational performance. Academy of Management Review 26 3, pp. 446-456.

DiMaggio, P. J. and Powell, W. W., 1983. The iron cage revisited: institutional isomorphism and collective rationality in organizational fields. American Sociological Review 48, pp. 147-160.

Doll Jr., W. E., 1989. Complexity in the classroom. Educational Leadership 47 1, pp. 65-70.

Donaldson, L., 1996. For positivist organization theory: proving the hard core, Sage Publications, London.

Ehrhart, M. and Klein, K., 2001. Predicting followers' preferences for charismatic leadership: the influence of follower values and personality. Leadership Quarterly 12 2, pp. 153-179.

Ezzamel, M. and Willmott, H., 1998. Accounting for teamwork: a critical study of the groupbased systems of organizational control. Administrative Science Quarterly 43, pp. 358-396. 
Ferguson, R. F., 1991. Paying for public education: new evidence on how and why money matters. Harvard Journal on Legislation 28, pp. 465-498.

Gardner, W. L. and Avolio, B. J., 1998. The charismatic relationship: A dramaturgical perspective. Academy of Management Review 23, pp. 32-58.

Gell-Mann, M., 1994. The quark and the jaguar, W. H. Freeman, New York.

Gerstner, C. and Day, D., 1997. Meta-analytic review of leader-member exchange theory: correlates and construct issues. Journal of Applied Psychology 82 6, pp. 827-844.

Gibbs, J. W., 1902. Elementary principles in statistical mechanics, Scribner's, New York.

Gnyawali, D. and Madhavan, R., 2001. Cooperative networks and competitive dynamics: a structural embeddedness perspective. Academy of Management Journal 26 3, pp. 431-445.

Goldstein, J. A., 1995. The Tower of Babel in nonlinear dynamics: toward a clarification of terms. In: Robertson, R. and Combs, A., Editors, 1995. Chaos in psychology and the life sciences: proceedings of the society for chaos theory in psychology and the life sciences, Lawrence Erlbaum Associates, Mahwah, NJ, pp. 39-47.

Goldstein, J. A., 1995. Using the concept of self-organization to understand social system change: strengths and limitations. In: Albert, A., Editor, , 1995. Chaos and society, IOS Press, Amsterdam, pp. 49-62.

Goldstein, J. A., 1996. Causality and emergence in chaos and complexity theories. In: Sullis, W., Editor, , 1996. Nonlinear dynamics and human behavior, World Scientific Publishing, Singapore.

Graen, G. and Uhl-Bien, M., 1995. Relationship-based approach to leadership: development of leader-member exchange LMX theory of leadership over 25 years: applying a multi-level multi-domain perspective. Leadership Quarterly 6 2, pp. 219-247. Abstract

Guastello, S. J., 1987. A butterfly catastrophe model of motivation in organizations: academic performance. Journal of Applied Psychology 72 1, pp. 165-182.

Guastello, S. J., 1992. Population dynamics and workforce productivity. In: Michaels, M., Editor, , 1992. Proceedings of the annual chaos network conference: the second iteration, People Technologies, Urbana, pp. 120-127.

Hackman, J. R., 1986. The psychology of self-management in organizations. In: Pollack, M. S. and Perloff, R. O., Editors, 1986. Psychology and work: productivity, change, and employment, American Psychological Association, Washington, DC, pp. 85-136.

Hater, J. and Bass, B., 1988. Superiors' evaluations and subordinates' perceptions of transformational and transactional leadership. Journal of Applied Psychology 73, pp. 695-702.

Holland, J. H., 1995. Hidden order, Addison-Wesley Publishing, Reading, MA.

Hollander, E. A., 1978. Leadership dynamics: A practical guide to effective relationships, Free Press, New York.

House, R. J., Spangler, D. and Woycke, J., 1991. Personality and charisma in the U.S. Presidency: A psychological theory of leadership effectiveness. Administrative Science Quarterly 36, pp. 364-396.

Howell, J. M. and Frost, P. J., 1989. A laboratory study of charismatic leadership. Organizational Behavior and Human Decision Processes 43, pp. 243-269.

Hunt, J. G., 1991. Leadership: a new synthesis, Sage, Newbury Park, CA.

Hunt, J. G., 1999. Transformational/charismatic leadership's transformation of the field: an historical essay. Leadership Quarterly 10 2, pp. 129-144.

Hunt, J. G. and Dodge, G. E., 2000. Leadership déjà vu all over again. Leadership Quarterly Yearly Review of Leadership 11 4, pp. 435-458.

Hunt, J. G., \& Ropo, A. (in press). Longitudinal organizational research and the third scientific discipline. Group and Organization Management.

Ilgen, D. R. and Hulin, C. L., Editors, 2000. Computational modeling of behavior in organizations: the third scientific discipline, American Psychological Association, Washington, DC.

Jacobs, T. O. and Jaques, E., 1987. Leadership in complex systems. In: Zeidner, J., Editor, , 1987. Human productivity enhancement vol. 2, Praeger, New York, pp. 7-65. 
Jaques, E., 1990. In praise of hierarchy. Harvard Business Review 68 1, pp. 137-143.

Jehn, K. A., 1997. A qualitative analysis of conflict types and dimensions in organizational groups. Administrative Science Quarterly 42, pp. 530-557.

Katz, D and Kahn, R., 1978. The social psychology of organizations (2nd ed.),, Wiley, New York.

Kauffman, S. A., 1986. Autocatalytic sets of proteins. Journal of Theoretical Biology 119, pp. 1-24.

Kauffman, S. A., 1993. The origins of order, Oxford University Press, New York.

Kauffman, S. A., 1995. At home in the universe: the search for the laws of self-organization and complexity, Oxford University Press, New York.

Kerr, S. and Jermier, J., 1978. Substitutes for leadership: their meaning and measurement. Organizational Behavior and Human Performance 22, pp. 375-403.

Kirkpatrick, S. A. and Locke, E. A., 1996. Direct and indirect effects of three core charismatic leadership components on performance and attitudes. Journal of Applied Psychology 81 1, pp. 36-61.

Leana, C. R. and Rousseau, D., 2000. Relational wealth: the advantages of stability in a changing economy, Oxford University Press, Oxford.

Leana, C. R. and Van Buren III, H. J., 1999. Organizational social capital and employment practices. Academy of Management Review 24, pp. 538-555.

Levin, M., 1993. Creating networks for rural economic development in Norway. Human Relations 46 2, pp. 193-219.

Levy, S., 1992. Artificial life: the quest for new creation, Random House, New York.

Manz, C. and Sims, H., 1984. Searching for the unleader: organizational member views on leading self-managed groups. Human Relations 37, pp. 409-424.

Manz, C. and Sims, H., 1987. Leading workers to lead themselves: the external leadership of self-managed work teams. Administrative Science Quarterly 32, pp. 106-128.

Marion, R., 1999. The edge of organization: chaos and complexity theories of formal social organization, Sage, Newbury Park, CA.

Marion, R. and Bacon, J., 1999. Organizational extinction and complex systems. Emergence: A Journal of Complexity Issues in Organizations and Management 14, pp. 71-96.

Masterson, S., 2000. Integrating justice and social exchange: the differing effects of fair procedures and treatment on work relationships. Academy of Management Journal 43 4, pp. 738-749.

McKelvey, B. (in press). MicroStrategy from MacroLeadership: distributed intelligence via new science. In: A. Y. Lewin, \& H. Volberda (Eds.), Mobilizing the self-renewing organization. Thousand Oaks, CA: Sage.

Meindl, J. R., Erlich, S. B. and Dukerich, J. M., 1985. The romance of leadership. Administrative Science Quarterly 30, pp. 78-102.

Nahapiet, J. and Ghoshal, S., 1998. Social capital, intellectual capital, and the organizational advantage. Academy of Management Review 23, pp. 242-266.

Nicolis, G. and Prigogine, I., 1989. Exploring complexity, Freeman, San Francisco, CA.

Nowak, M. A., May, R. M. and Sigmund, K., 1995. The arithmetics of mutual help. Scientific American 272 6, pp. 76-81.

Omnès, R., 1999. Understanding quantum mechanics, Princeton University Press, Princeton, NJ.

Pillai, R. and Meindl, J., 1998. Context and charisma: a "meso" level examination of the relationship of organic structure, collectivism, and crisis to charismatic leadership. Journal of Management 245 , pp. 643-671.

Poincaré, H., Editor, , 1992. New methods of celestial mechanics Vol. 13, Springer-Verlag, New York, NY.

Prigogine, I., 1997. The end of certainty, Free Press, New York.

Regine, B. and Lewin, R., 2000. Leading at the edge: how leaders influence complex systems. Emergence: A Journal of Complexity Issues in Organizations and Management 2 2, pp. 5-23.

Reynolds, C., 1987. Flocks, herds, and schools: a distributed behavioral model. Computer Graphics 2125, p. 32. 
Richardson, K. and Cilliers, P., 2001. Special editors introduction: what is complexity science? A view from different directions. Emergence: A Journal of Complexity Issues in Organizations and Management 31, pp. 5-23.

Schein, E. H., 1992. Organizational culture and leadership (2nd ed.)," Jossey-Bass, San Francisco.

Scott, W. R., 1987. Organizations: rational, natural, and open systems (2nd ed.),, Prentice-Hall, Englewood Cliffs, NJ.

Senge, P. M., 1990. The fifth discipline: the art and practice of the learning organization, Random House, New York.

Settoon, R., Bennett, N., and Liden, R., 1996. Social exchange in organizations: perceived organizational support, leader-member exchange, and employee reciprocity. Journal of Applied Psychology 81 3, pp. 219-227.

Singh, J. V., Tucker, D. J., and House, R. J., 1986. Organizational legitimacy and the liability of newness. Administrative Science Quarterly 31, pp. 171-193.

Smith, A. (1799). An inquiry into the nature and causes of the wealth of nations. London, 1776.

Sterman, J. D., 1994. Learning in and about complex systems. System Dynamics Review 10, pp. 291-330.

Thomas, K. and Velthouse, B., 1990. Cognitive elements of empowerment: an "interpretive" model of intrinsic task motivation. Academy of Management Review 15, pp. 666-681.

Uhl-Bien, M., Graen, G. B., and Scandura, T., 2000. Implications of leader-member exchange LMX for strategic human resource management systems: relationships as social capital for competitive advantage. In: Ferris, G., Editor, , 2000. Research in personnel and human resource management Vol. 18, JAI Press, Greenwich, CT, pp. 137-185.

Waldrop, M. M., 1992. Complexity: the emerging science at the edge of order and chaos, Simon and Schuster, New York.

Walton, R., 1985. From control to commitment in the workplace. Harvard Business Review 632 , pp. 76-84.

Weick, K. E., 1976. Educational organizations as loosely coupled systems. Administrative Science Quarterly 21, pp. 1-19.

Weick, K. E., 1979. The social psychology of organizing, Addison Wesley, Reading, MA.

Wheatley, M. J., 1992. Leadership and the new science: learning about organization from an orderly universe, Berrett-Koehler, San Francisco, CA. 